\title{
Low temperature amorphous and nanocrystalline silicon thin film transistors deposited by Hot-Wire CVD on glass substrate
}

\author{
M. Fonrodona ${ }^{1}$, D. Soler ${ }^{1}$, J. Escarré ${ }^{1}$, F. Villar ${ }^{1}$, J. Bertomeu $^{1}$ and J. Andreu ${ }^{1}$
}

A. Saboundji ${ }^{2}$, N. Coulon ${ }^{2}$ and T. Mohammed-Brahim ${ }^{2}$

${ }^{1}$ CeRMAE - Departament de Física Aplicada i Òptica, Universitat de Barcelona, Av. Diagonal 647, 08028 Barcelona, Spain .

${ }^{2}$ Groupe de Microélectronique, IETR UMR-CNRS 6164, Université de Rennes 1, 35042 Rennes Cedex, France

\begin{abstract}
Amorphous and nanocrystalline silicon films obtained by Hot-Wire Chemical Vapor deposition have been incorporated as active layers in n-type coplanar top gate thin film transistors deposited on glass substrates covered with $\mathrm{SiO}_{2}$. Amorphous silicon devices exhibited mobility values of $1.3 \mathrm{~cm}^{2} \mathrm{~V}^{-1} \mathrm{~s}^{-1}$, which are very high taking into account the amorphous nature of the material. Nanocrystalline transistors presented mobility values as high as $11.5 \mathrm{~cm}^{2} \mathrm{~V}^{-1} \mathrm{~s}^{-1}$ and resulted in low threshold voltage shift $(\sim 0.5 \mathrm{~V})$.
\end{abstract}

\section{Keywords}

Thin film transistor, Amorphous and nanocrystalline silicon, Hot-Wire CVD 


\section{Introduction}

Nowadays, the electronic devices used to process the signal given by mechanical, chemical or biological functions need to be made on the same substrate used for these other functions. In many cases, the substrate is a glass or a plastic that does not support high temperatures. In particular, thin film transistors (TFTs) are widely used as active elements in active-matrix liquid crystal displays (AMLCDs) applications in flat panel displays (FPDs) like portable laptop computers, mobile phones and personal digital assistants (PDAs) [1].

This need to obtain TFTs at low substrate temperatures has drawn the attention to silicon deposition techniques like Hot-Wire Chemical Vapor Deposition (HWCVD), as they allow device-quality material deposition of both amorphous $(\mathrm{a}-\mathrm{Si}: \mathrm{H})$ and nanocrystalline (nc-Si:H) silicon thin films at substrate temperatures $\left(T_{s}\right)$ below $300^{\circ} \mathrm{C}$. Using higher substrate temperatures, mobilities $(\mu)$ of around $0.7 \mathrm{~cm}^{2} \mathrm{~V}^{-1} \mathrm{~s}^{-1}$ for a-Si:H [2] and $1.4 \mathrm{~cm}^{2} \mathrm{~V}^{-1} \mathrm{~s}^{-1}$ for heterogeneous silicon (het-Si:H) [3] both deposited by HWCVD have been shown in bottom gate structures. Regarding nc-Si:H, mobility values as high as $40 \mathrm{~cm}^{2} \mathrm{~V}^{-1} \mathrm{~s}^{-1}$ have been reported for staggered top gate bottom source/drain geometry using Very High Frequency (VHF) Plasma Enhanced CVD (PECVD) at $150^{\circ} \mathrm{C}[4]$.

In this paper we focus on the fabrication of coplanar top gate TFTs based on HWCVD a-Si:H and nc-Si:H deposited on $\mathrm{SiO}_{2}$ coated glass.

\section{Experimental}

Top gate TFTs have been processed using 200 nm-thick a-Si:H or nc-Si:H silicon films deposited by HWCVD in a multichamber deposition set-up described elsewhere [5] on $2 \times 2$ square inch glass substrates covered with $200 \mathrm{~nm}$ Atmospheric Pressure CVD (APCVD) deposited $\mathrm{SiO}_{2}$. a-Si:H has been deposited at a filament temperature $\left(\mathrm{T}_{\mathrm{f}}\right)$ of around $1680^{\circ} \mathrm{C}$, a substrate temperature of $200^{\circ} \mathrm{C}$, process pressure $(\mathrm{P})$ of $1 \cdot 10^{-2}$ mbar and without any hydrogen dilution $\left(\mathrm{D}_{\mathrm{H}}\right)$, whereas slightly lower filament temperature $\left(\mathrm{T}_{\mathrm{f}} \sim 1610^{\circ} \mathrm{C}\right), \mathrm{P}=3 \cdot 10^{-2} \mathrm{mbar}$ and $\mathrm{D}_{\mathrm{H}}=95 \%\left(4 \mathrm{sccm} \mathrm{SiH}_{4}\right.$ and $\left.76 \mathrm{sccm} \mathrm{H}_{2}\right)$ were used in the case of the nc-Si:H layers. A $150 \mathrm{~nm}$ thick n-type nc-Si:H layer was deposited on top of the a-Si:H or nc-Si:H layer by adding $\mathrm{PH}_{3}$ to the gas mixture so that $[\mathrm{P}] /[\mathrm{Si}]$ was $2 \%$ in the gas phase (the rest of the deposition conditions 
were the same as those of undoped nc-Si:H). In amorphous TFTs, undoped a-Si:H and n-type nc-Si:H layers were deposited in different chambers, whereas in the case of nc-Si:H ones, deposition of all HWCVD layers took place in the same chamber, just closing the shutter a few seconds to avoid the pressure peak upon the inclusion of $\mathrm{PH}_{3}$ in the gas mixture.

The previous stack of undoped and doped films was processed to fabricate n-type TFTs in the configuration presented in Fig. 1. The doped nc-Si:H layer was plasma etched to define channel, source and drain regions for each transistor. Then, a $100 \mathrm{~nm}$-thick $\mathrm{SiO}_{2}$ layer was deposited by RF sputtering to ensure the gate insulation.

The gate insulator fabrication is, therefore, the most critical step that determines the success of the TFT process. Particularly, it is very difficult to obtain high quality gate insulators at low temperature. Deposition and treatment conditions have been optimized to lead to RF sputtered $\mathrm{SiO}_{2}$ film with gate insulator quality. It was deposited using an $\mathrm{Ar} / \mathrm{O}_{2}$ mixture and without heating the substrate holder, so the temperature reached by the film during deposition was around $80^{\circ} \mathrm{C}$. Metal- $\mathrm{SiO}_{2}-\mathrm{Si}$ capacitances processed using the present silicon dioxide showed a flat-band voltage of $-0.2 \mathrm{~V}$ and an interface state density $\mathrm{D}_{\mathrm{it}}=6.4 \cdot 10^{10} \mathrm{eV}^{-1} \mathrm{~cm}^{-2}$. These values are given here to show the high quality of the silicon dioxide and the $\mathrm{SiO}_{2} / \mathrm{Si}$ interface .

After $\mathrm{SiO}_{2}$ deposition, source and drain contacts were opened through the gate insulator. Finally, aluminum was thermally evaporated and wet etched to form source, drain and gate electrodes. Post-metallization annealing was performed at $200^{\circ} \mathrm{C}$ in an atmosphere of forming gas.

TFTs with different channel length (L) and width (W) were simultaneously fabricated. L varied from 20 to $80 \mu \mathrm{m}$ and $\mathrm{W}$ between 20 and $100 \mu \mathrm{m}$. TFTs were characterized at $25^{\circ} \mathrm{C}$ and then the usual device parameters were determined: threshold voltage $\left(\mathrm{V}_{\mathrm{T}}\right)$, transconductance $\left(g_{m}\right)$, field effect mobility $(\mu)$ and inverse subthreshold slope $(S)$. $V_{T}$ and $g_{m}$ were deduced in the linear regime (low drain-source voltage, $\mathrm{V}_{\mathrm{DS}}$ ),

$$
\mathrm{I}_{\mathrm{DS}}=\mu \cdot \frac{\mathrm{W}}{\mathrm{L}} \cdot \mathrm{C}_{\mathrm{ox}} \cdot \mathrm{V}_{\mathrm{DS}} \cdot\left(\mathrm{V}_{\mathrm{GS}}-\mathrm{V}_{\mathrm{T}}\right)
$$

where $\mathrm{V}_{\mathrm{T}}$ is the intercept of the transfer characteristics $\left(\mathrm{I}_{\mathrm{DS}}\left(\mathrm{V}_{\mathrm{GS}}\right)\right.$ ) with the gate voltage $\left(\mathrm{V}_{\mathrm{GS}}\right)$ axis, and $g_{m}$ is the slope of the linear fit. $\mu$ is then deduced from the relation: 


$$
\mu=g_{m} \cdot(L / W) \cdot\left(1 / C_{o x}\right) \cdot\left(1 / V_{D S}\right)
$$

where $\mathrm{C}_{\mathrm{ox}}$ is the gate oxide capacitance per area unit, $\mathrm{C}_{\mathrm{ox}}=\left(\varepsilon_{0}{ }^{\cdot} \varepsilon_{\mathrm{ox}}\right) / \mathrm{t}_{\mathrm{ox}}$, being $\mathrm{t}_{\mathrm{ox}}$ the oxide thickness. $\mathrm{S}$ is the inverse slope of the transfer characteristics using logarithmic plot. Finally, stress experiments were performed using a negative gate voltage of $-10 \mathrm{~V}$.

\section{Results and discussion}

\subsection{Material characterization}

Fig. 2 shows the Raman spectra of two silicon samples (a-Si:H and nc-Si:H) deposited at the same conditions as the ones used in the TFTs under study. In the case of the nc-Si:H layer, a crystalline fraction $\left(\mathrm{X}_{\mathrm{c}}\right.$, calculated as the weight of the crystalline contribution $\left(520 \mathrm{~cm}^{-1}\right)$ in the Raman spectra) of approximately 0.50 was measured in a $400 \mathrm{~nm}$-thick layer (thicker than those used in the studied TFTs). When implemented to completely Hot-Wire deposited p-i-n nc-Si:H solar cells, this material has led to stable devices [6].

Regarding the n-type doped material, characterization of a $40 \mathrm{~nm}$-thick n-layer grown in the above-mentioned conditions resulted in a dark conductivity $\left(\sigma_{\mathrm{d}}\right)$ of $5 \Omega^{-1} \mathrm{~cm}^{-1}$, an activation energy $\left(E_{a}\right)$ of $0.02 \mathrm{eV}$ and $X_{c}=0.43$.

\section{2. a-Si:H TFTs}

Fig. 3 shows the typical transfer characteristics of the amorphous silicon TFTs. It is clear from this curve that both $\mathrm{S}$ and $\mathrm{V}_{\mathrm{T}}$ were low, thus ensuring a fast transition between the "on" and "off" states. Table 1 summarizes the mean parameters deduced from the characteristics of about thirty TFTs.

The determined values confirm the first observation of the transfer characteristics. Moreover, the mobility value can be considered as very high for a-Si:H devices if we compare them with values commonly found in literature [1,2]. This result is very interesting especially if we consider that $\mu=1.3 \mathrm{~cm}^{2} \mathrm{~V}^{-1} \mathrm{~s}^{-1}$ is a mean value.

\section{3. nc-Si:H TFTs}


Results regarding the nc-Si:H TFTs can be seen in Fig. 4, where the transfer characteristics of two devices with different $\mathrm{W} / \mathrm{L}$ ratios are shown. The mean parameters obtained in this case are also presented in Table 1.

Excellent subthreshold slope $(0.34 \mathrm{~V} / \mathrm{dec})$ and mobility values $\left(\sim 11.5 \mathrm{~cm}^{2} \mathrm{~V}^{-1} \mathrm{~s}^{-1}\right)$ were obtained. Such $\mu$ values highly improve the application field of nc-Si:H TFTs. As an example, the active matrix addressing of Organic Light Emitting Diodes (OLED) flat panel can use such high mobility TFTs, as it requires high mobility to produce enough current, high uniformity of the TFTs performance on large area, and a process using deposition conditions similar to that of a-Si:H. All these needs are fulfilled by the present HWCVD-deposited nc-Si:H TFTs.

\subsection{Stability under gate bias stress}

In order to study their stability, both a-Si:H and nc-Si:H TFTs were stressed under $-10 \mathrm{~V}$ gate bias. Fig. 5 shows the variation of the threshold voltage under stress for both kinds of transistors. As expected, the $\mathrm{V}_{\mathrm{T}}$ shift was more pronounced in the case of a-Si:H devices $\left(\Delta \mathrm{V}_{\mathrm{T}} \sim 5 \mathrm{~V}\right)$, pointing to stability problems most likely attributable to meta-stable defect creation in the material [7], what can be related to the high hydrogen $\left(\mathrm{C}_{\mathrm{H}} \sim 12 \%\right)$ content measured in a-Si:H films deposited in the same conditions as those implemented in the devices under study. Conversely, nc-Si:H TFTs showed superior stability against gate bias stress. The small $\mathrm{V}_{\mathrm{T}}$ shift observed in this case $\left(\Delta \mathrm{V}_{\mathrm{T}} \sim 0.5 \mathrm{~V}\right)$, imputable to the disordered structure of nc-Si:H [8], is another argument to use these TFTs in the OLED addressing.

\section{Conclusions}

Amorphous and nanocrystalline silicon thin films deposited by Hot-Wire CVD at low substrate temperature $\left(200^{\circ} \mathrm{C}\right)$ have been successfully implemented in coplanar top gate n-type TFTs. Layers were deposited onto $\mathrm{SiO}_{2}$ coated glass and gate insulation was achieved by means of high quality RF sputtered $\mathrm{SiO}_{2}$.

a-Si:H devices exhibited mobility values of $1.3 \mathrm{~cm}^{2} \mathrm{~V}^{-1} \mathrm{~s}^{-1}$, which are very high taking into account the amorphous nature of the material. nc-Si:H TFTs presented mobility values as high as $11.5 \mathrm{~cm}^{2} \mathrm{~V}^{-1} \mathrm{~s}^{-1}$ and resulted in low threshold voltage shift $(\sim 0.5 \mathrm{~V})$, what made them suitable to be used in the OLED addressing. 


\section{Acknowledgements}

The work at UB is financially supported by the CICYT of the Spanish Government (MAT2001-3541-C03-01).

\section{References}

1. S. Wagner, H. Gleskova, I-C. Cheng, M. Wu, Thin Solid Films 430 (2003) 15.

2. B. Stannowski, R.E.I Schropp, R.B. Wehrspohn, M. J. Powell, J. Non-Cryst. Solids 299-302 (2002) 1340.

3. B. Stannowski, A.M. Brockhoff, A. Nascetti, R.E.I. Schropp, J. Non-Cryst. Solids 266-269 (2000) 464.

4. I-C. Cheng, S. Wagner, IEE Proc.-Circuits Devices Syst., 150 (2003) 339.

5. C. Voz, D. Peiró, J. Bertomeu, D. Soler, M. Fonrodona, J. Andreu, Mater. Sci. Eng. B69-70 (2000) 278.

6. M. Fonrodona, D. Soler, J.M. Asensi, J. Bertomeu, J. Andreu, in: K. Kurokawa, L.L. Kazmerski, B. McNelis, M. Yamaguchi, C. Wronski, W.C. Sinke (Eds.), Proceedings of the 3rd World Conference on Photovoltaic Energy Conversion, Osaka, Japan, May 11-18, 2003, p. 1768. 7. B. Stannowski, R.E.I. Schropp, Thin Solid Films 383 (2001) 125.

8. T. Mohammed-Brahim, A. Rahal, G. Gautier, F. Raoult, H. Toutah, B. Tala-Ighil, J.F. Llibre, J. Non-Cryst. Solids 299-302 (2002) 497. 
HW3-57

\section{List of table and figure captions}

Table 1 Mean parameters measured for a-Si:H and nc-Si:H TFTs.

Fig. 1 Cross-section of the n-type top gate coplanar TFTs.

Fig. 2 Raman spectra of a-Si:H and nc-Si:H layers deposited at the same conditions that those implemented in the TFTs.

Fig. 3 Transfer characteristics of a HWCVD a-Si:H TFT.

Fig. 4 Transfer characteristics of HWCVD-deposited nc-Si:H TFTs with different W/L ratios.

Fig. 5 Threshold voltage shift under $-10 \mathrm{~V}$ gate bias for both a-Si:H and nc-Si:H TFTs. 
HW3-57

Table 1

\begin{tabular}{|c|c|c|c|}
\hline & $\mu\left(\mathrm{cm}^{2} \mathrm{~V}^{-1} \mathrm{~s}^{-1}\right)$ & $\mathrm{S}(\mathrm{V} / \mathrm{dec})$ & $\mathrm{V}_{\mathrm{T}}(\mathrm{V})$ \\
\hline $\mathrm{a}-\mathrm{Si}: \mathrm{H}$ & 1.3 & 0.60 & 3.47 \\
\hline nc-Si:H & 11.5 & 0.34 & 5.70 \\
\hline
\end{tabular}


Figure 1
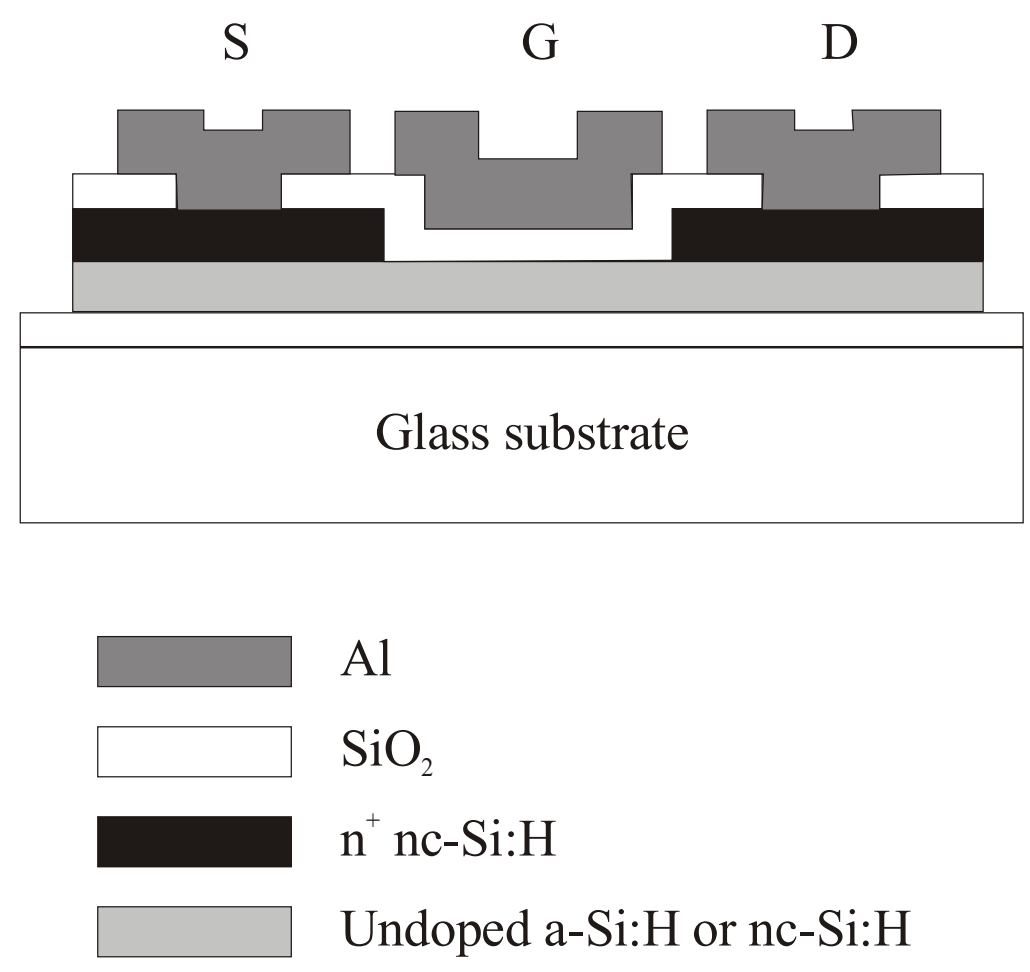
HW3-57

Figure 2

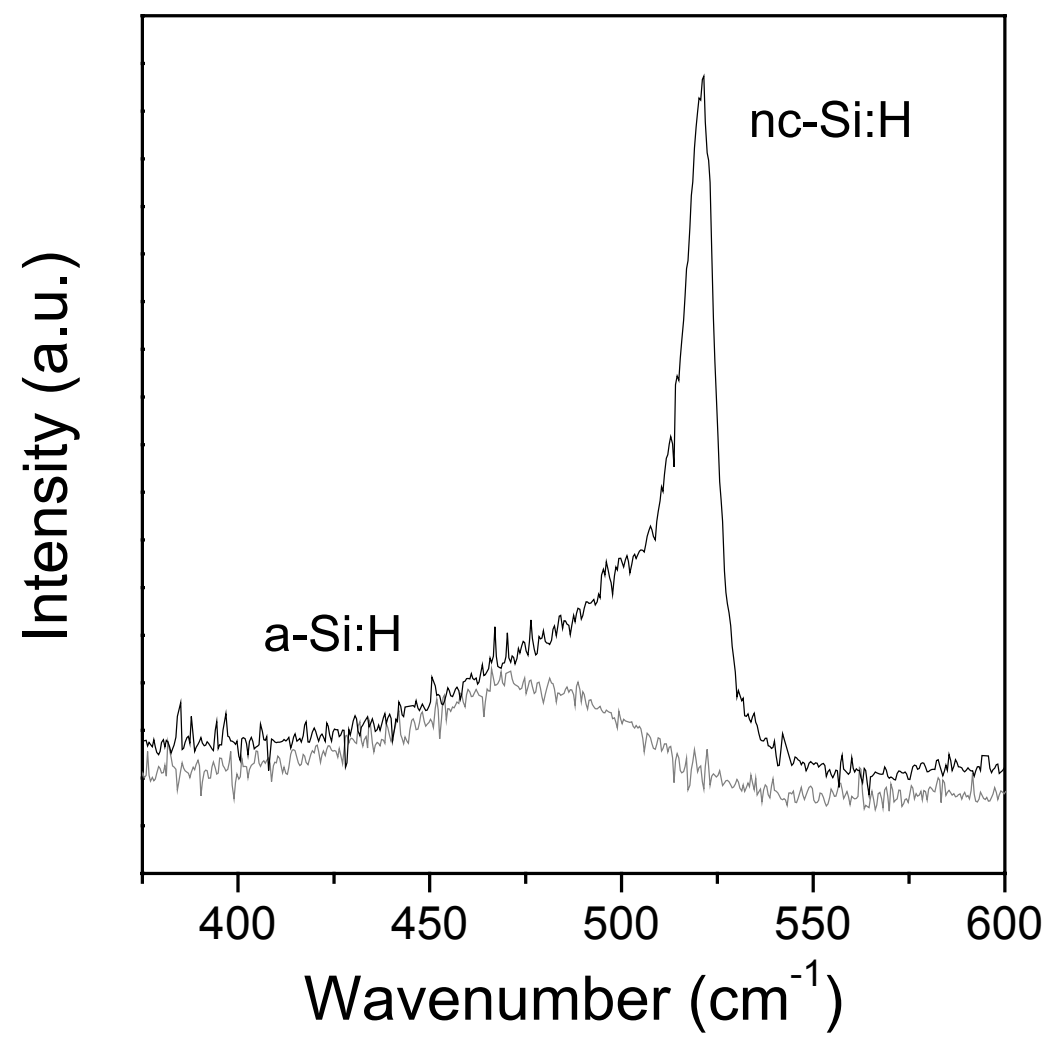


HW3-57

Figure 3

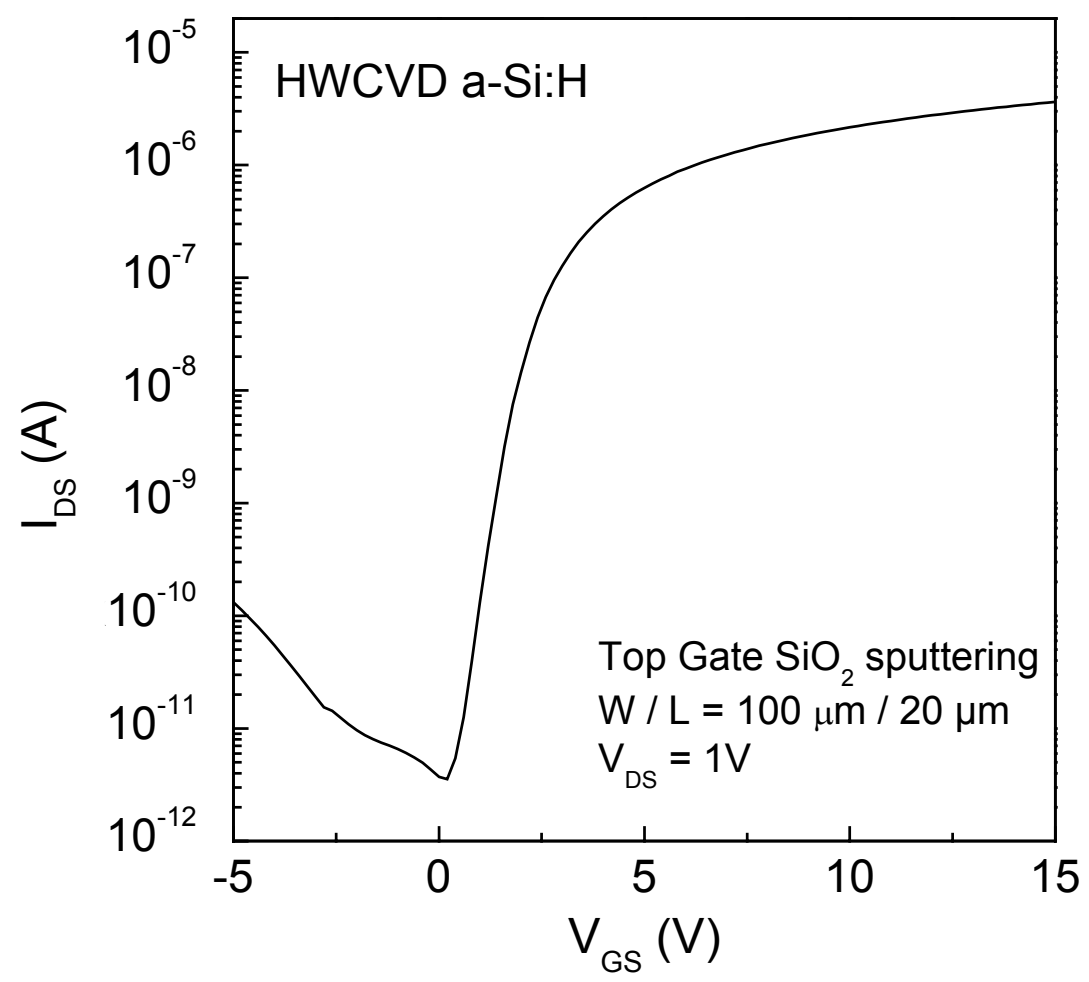


HW3-57

Figure 4

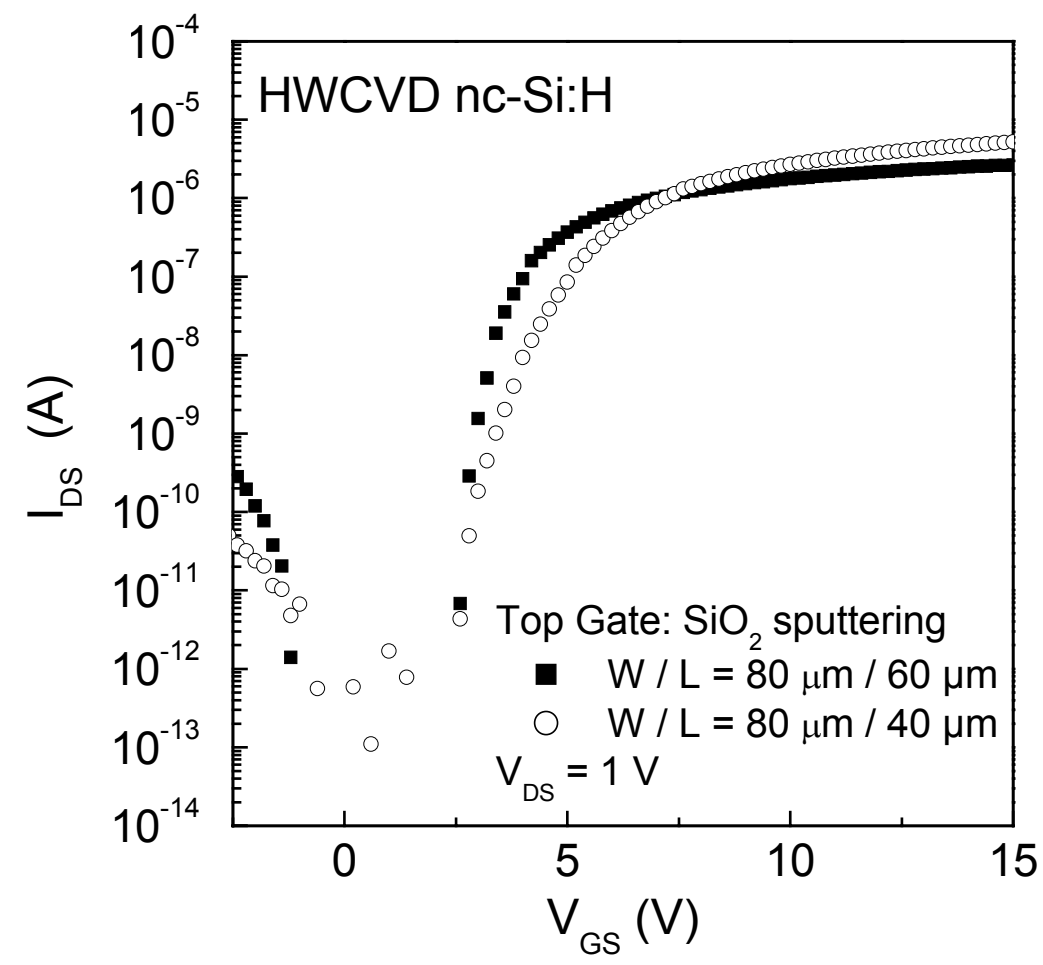


HW3-57

Figure 5

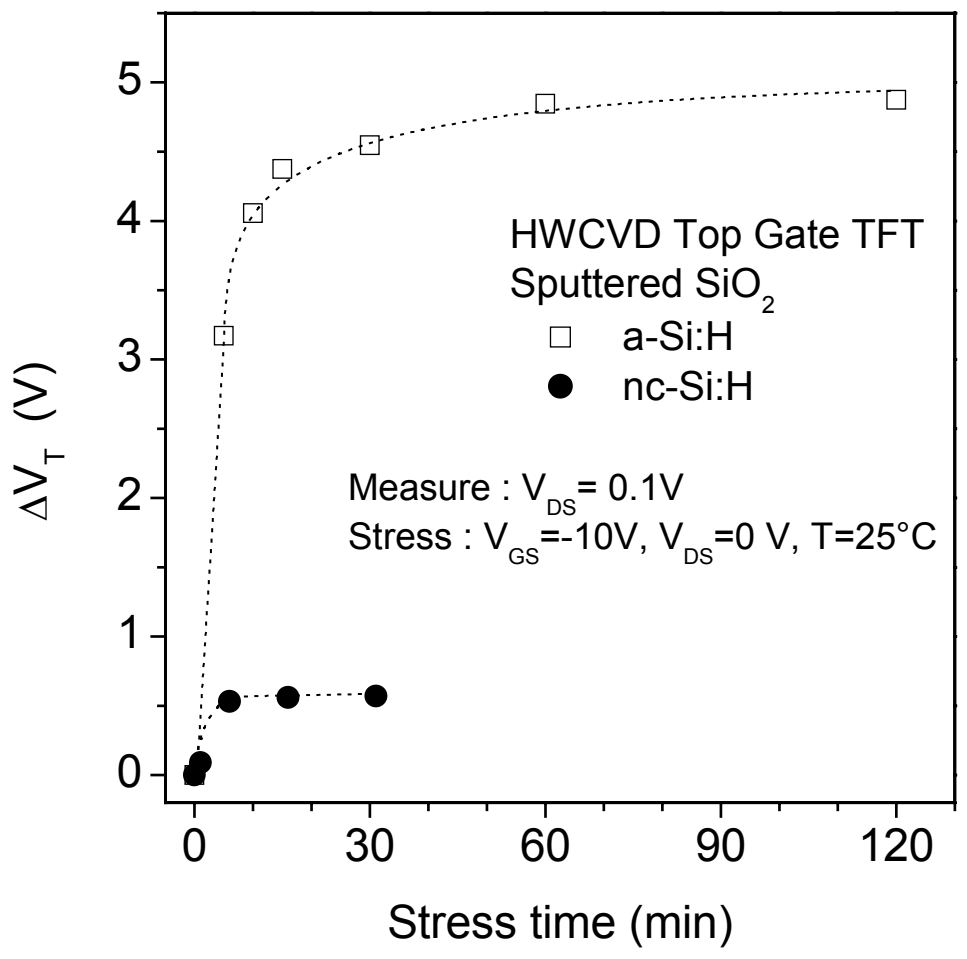

